Western University

Scholarship@Western

Lifestyle Research Team

Fall 12-17-2017

\title{
Multiple-Modality Exercise And Mind-Motor Training To Improve Mobility In Older Adults: A Randomized Controlled Trial
}

Narlon Cassio Boa Sorte Silva

nboasort@uwo.ca

Dawn P. Gill

Western University

Michael A. Gregory

Western University

John Bocti

Western University

Robert Petrella

Western University

Follow this and additional works at: https://ir.lib.uwo.ca/petrellateampub

Part of the Community Health and Preventive Medicine Commons, Rehabilitation and Therapy Commons, and the Sports Sciences Commons

Citation of this paper:

Boa Sorte Silva, Narlon Cassio; Gill, Dawn P.; Gregory, Michael A.; Bocti, John; and Petrella, Robert, "Multiple-Modality Exercise And Mind-Motor Training To Improve Mobility In Older Adults: A Randomized Controlled Trial" (2017). Lifestyle Research Team. 4. https://ir.lib.uwo.ca/petrellateampub/4 
Multiple-modality exercise and mind-motor training to improve mobility in older

Narlon C Boa Sorte Silva ${ }^{1,2}$

Dawn P Gill $2,3,4,6$

Michael A Gregory $2,3,5,6$

John Bocti ${ }^{1,2}$

Robert J Petrella ${ }^{1,2,3,7,8^{*}}$

${ }^{1}$ School of Kinesiology, Faculty of Health Sciences, Western University, London, ON, Canada

$11{ }^{2}$ Lawson Health Research Institute, London, ON, Canada

12 3ealth \& Rehabilitation Sciences, Faculty of Health Sciences, Western University, London, ON,

13 Canada

$14{ }^{4}$ School of Health Studies, Faculty of Health Sciences, Western University, London, ON, Canada

$15{ }^{5}$ Cognitive Health and Aging Research Lab, Montreal Heart Institute, Montreal, QC, Canada

$16{ }^{6}$ Biomedical Sciences, Faculty of Medicine, University of Montreal, Montreal, QC, Canada

$17{ }^{7}$ Centre for Studies in Family Medicine, Department of Family Medicine, Western University, 18 London, ON, Canada

$19{ }^{8}$ Canadian Centre for Activity and Aging, Western University, London, ON, Canada

${ }^{1}$ This work was conducted at the Parkwood Research Institute, in affiliation with the Lawson Health Research Institute and St. Joseph's Health Care (London, ON, Canada).

2Part of the data in this manuscript was presented by Mr. Boa Sorte Silva at the Alzheimer's Association International Conference in Toronto, Canada. July, 2016.

*Corresponding author:

28 Robert J Petrella, MD, PhD, FACSM, FCFP

29 Centre for Studies in Family Medicine

30 Western Centre for Public Health and Family Medicine, 2nd Floor

31 Western University

321465 Richmond St.

33 London, ON N6G 2M1, Canada

34 Tel.: +1 5196612111 Ext.: 22119

35 Fax: +1 5198585167

36 E-mail: Robert.Petrella@schulich.uwo.ca 


\section{Abstract}

38 Objective: To investigate the effects of multiple-modality exercise with or without additional

39 mind-motor training on mobility outcomes in older adults with subjective cognitive complaints.

40 Methods: This was a 24-week randomized controlled trial with a 28-week no-contact follow-up.

41 Community-dwelling older adults underwent a thrice -weekly, Multiple-Modality exercise and

42 Mind-Motor (M4) training or Multiple-Modality (M2) exercise with an active control

43 intervention (balance, range of motion and breathing exercises). Study outcomes included

44 differences between groups at 24 weeks and after the no-contact follow-up (i.e., 52 weeks) in

45 usual and dual-task (DT, i.e., serial sevens [S7] and phonemic verbal fluency [VF] tasks) gait

46 velocity, step length and cycle time variability, as well as DT cognitive accuracy.

47 Results: 127 participants (mean age 67.5 [7.3] years, 71\% women) were randomized to either

48 M2 $(n=64)$ or M4 $(n=63)$ groups. Participants were assessed at baseline, intervention endpoint

49 (24 weeks), and study endpoint (52 weeks). At 24 weeks, the M2 group demonstrated greater

50 improvements in usual gait velocity, usual step length, and DT gait velocity (VF) compared to

51 the M4 group, and no between- or within-group changes in DT accuracy were observed. At 52

52 weeks, the M2 group retained the gains in gait velocity and step length, whereas the M4 group

53 demonstrated trends for improvement $(\mathrm{p}=.052)$ in DT cognitive accuracy $(\mathrm{VF})$.

54 Conclusions: Our results suggest that additional mind-motor training was not effective to

55 improve mobility outcomes. In fact, participants in the active control group experienced greater

56 benefits as a result of the intervention.

57 Keywords: Dual-task gait, community-dwelling, multiple-modality, group-based exercise. 


\section{Introduction}

59 Older adults with subjective cognitive complaints (SCC) are at increased risk for future mobility

60 impairment (Allali et al., 2016) and cognitive decline (Jessen et al., 2014; Kaup et al., 2015).

61 Self-reported SCC may be the first indicator of underlying cognitive impairment (Amariglio et

62 al., 2012; Chao et al., 2010; Jessen et al., 2010) and have been associated with poorer scores on

63 objective cognitive assessments (Amariglio et al., 2011), as well as cortical and hippocampal

64 atrophy (Saykin et al., 2006). In this perspective, SCC is a clinically-relevant phenomenon that

65 can serve to identify individuals at-risk for more serious forms of cognitive impairment and

66 dementia, and these cognitive complaints have been found to predict future neuropathological

67 progression towards the establishment of dementia (Kaup et al., 2015). The current efforts to

68 improve cognition and mobility in Alzheimer's disease and other dementias have been met with

69 relatively little success (Brookmeyer et al., 2007; Sperling et al., 2011). Thus, directing

70 interventions towards individuals who are at increased risk for future pathological cognitive

71 decline (e.g., those with SCC) prior to the establishment of underlying neuropathological

72 changes to the brain may provide the greatest clinical benefit (Livingston et al., 2017).

73 Cognitive deficits in older adults have been strongly associated with poor performance in several

74 spatiotemporal gait characteristics, including slow velocity and increased stride time variability

75 (Montero-Odasso et al., 2014). Moreover, slow gait velocity is an early indicator of cognitive

76 impairment (Verghese et al., 2014) and is related to shortened life span (Studenski et al., 2011).

77 Further, gait variability is associated with increased risk of falls (Beauchet et al., 2013, 2009),

78 and higher gait variability is more apparent in those with a greater degree of cognitive

79 impairment (Montero-Odasso et al., 2012). In fact, slower gait velocity and increased gait

80 variability were linked to accentuated cognitive decline 25 years after baseline assessment in a 
81 recent retrospective investigation (MacDonald et al., 2017); however, the relationship between

82 cognitive functioning and gait performance has yet to be fully understood. The relationship is

83 thought to be mediated, at least in part, may be a result of poorer executive functioning (EF)

84 (Hausdorff et al., 2008) among healthy individuals (Allali et al., 2013) and those with severe

85 cognitive impairment (e.g., Alzheimer's disease) (Allali et al., 2007). The importance of

86 preserved EF in the cognitive control of gait becomes more evident under dual-task (DT)

87 conditions (e.g., walking and preforming a concurrent cognitive task) (Smith et al., 2016; Yogev-

88 Seligmann et al., 2008), where individuals with poorer EF demonstrate the most dramatic gait

89 impairments (Allali et al., 2010).

90 Early prevention strategies (prior to the establishment of permanent cognitive impairment) that

91 effectively improve usual and dual-task gait performance in those at greater risk for cognitive

92 impairment may preserve functional independence, reduce fall risk (Demnitz et al., 2016;

93 Snijders et al., 2007), and attenuate the increasing burden on health care systems associated with

94 mobility disability and dementia (Prince M, Wimo A, Guerchet M, 2015; Sperling et al., 2011).

95 Thus far, increasing evidence has suggested that habitual participation in exercise programs may

96 lead to improvements in usual and DT gait parameters (Dorfman et al., 2014; Hortobágyi et al.,

97 2015), static and dynamic balance (Zanotto et al., 2014); with a greater effect on frail individuals

98 (e.g., fallers, musculoskeletal disorders) and in those with neurological conditions (e.g., mild to

99 moderate dementia) (Gobbo et al., 2014; Zanotto et al., 2014). For instance, in a recent

100 laboratory-based investigation conducted by our research group, older adults with cognitive

101 impairment, not dementia (CIND) (Plassman et al., 2011) who underwent a combined 26-week

102 DT gait and aerobic exercise (AE) intervention (40 min/day, 3 days/week) demonstrated

103 significant improvements in usual and DT gait velocity and step length (Gregory et al., 2017). 
104 Despite promising evidence, the specific components of an exercise intervention that would

105 impart the greatest benefit to mobility impairments in older adults are yet to be defined (Young

106 et al., 2015). Furthermore, evidence is insufficient to conclude that a specific program of

107 cognitive training and/or exercise warrants prescription in individuals with SCC (Snowden et al.,

108 2011). Although the administration of exercise with (Plummer et al., 2015) or without

109 (Hortobágyi et al., 2015) additional DT gait training in previous exercise studies has been

110 associated with improved usual and DT gait performance, several aspects of these investigations

111 may raise concerns regarding the feasibility of exercise protocols administered in such laboratory

112 settings (i.e., translation to community settings). Further, most studies have failed to comply with

113 current guidelines for exercise in older adults with regards to exercise intensity, frequency and

114 duration (Hortobágyi et al., 2015; Plummer et al., 2015). These guidelines also emphasize the

115 importance of multiple-modality exercise programs over single-modality exercise programs to

116 enhance overall health and quality of life in the general population of older adults (Chodzko-

117 Zajko et al., 2009; Gregory et al., 2013), although evidence is still limited in more specific

118 groups (e.g., individuals with SCC). In addition, exploring the combination of multiple-modality

119 exercise with alternative, and perhaps more feasible (e.g., group-based, low-cost, and easily

120 administered), forms of mind-motor training (simultaneous cognitive and physical engagement)

121 on mobility outcomes may provide further support for optimal exercise interventions in older

122 adults at risk for cognitive and mobility impairment (Gregory et al., 2013).

123 Square-stepping exercise (SSE) is a group-based, low-intensity exercise program that has been

124 associated with improvements in lower extremity functional fitness and reduced fall risk in older

125 adults at high risk of falling (Shigematsu et al., 2008a). The SSE intervention is best

126 characterized as a visuospatial working memory task with a stepping response on a gridded floor 
127 mat, and thus, may be considered as a novel form of mind-motor training (Gill et al., 2016).

128 Recent evidence suggests that SSE may yield improvements in global and domain-specific

129 cognitive functioning, including EF subdomains (i.e., attention and mental flexibility) in older

130 adults free of dementia (Shigematsu, 2014; Teixeira et al., 2013). Nonetheless, the additive

131 effects of SSE on usual and DT spatiotemporal gait characteristics in combination with multiple-

132 modality exercise warrants further investigation.

133 Hence, the purpose of this study was to examine the influence of group-based, multiple-modality

134 exercise combined with mind-motor training (i.e., SSE), in comparison to multiple-modality

135 exercise with additional balance, range of motion and breathing exercises on spatiotemporal gait

136 characteristics in community-dwelling older adults with SCC. We hypothesized that the addition

137 of a mind-motor component to the multiple-modality exercise intervention would lead to greater

138 improvements in the study outcomes compared to multiple-modality exercise alone, particularly

139 by influence of SSE on neural control of gait.

140 2. Methods

142 The M4 Study was a two-arm randomized controlled trial (RCT) implementing a 24-week

143 intervention program with a 28-week no-contact follow-up (Gregory et al., 2016). Assessments

144 were performed at baseline, 24 weeks (intervention endpoint) and 52 weeks (study endpoint).

145 After baseline assessments, participants were randomized to either the multiple-modality

146 exercise with mind-motor training intervention group (Multiple-Modality, Mind-Motor [M4]) or

147 to the multiple-modality exercise active control group (Multiple-Modality [M2]). The

148 randomization sequence was computer generated, and concealed envelopes were used to assign

149 group status. All assessors were blinded to group assignment. 


\subsection{Participants}

151 Details of the M4 study participants and eligibility criteria have been published (Boa Sorte Silva

152 et al., 2017; Gregory et al., 2016). Briefly, the study included community-dwelling older adults

153 aged 55 years or older, who self-reported a cognitive complaint (defined answering positively to

154 the question “Do you feel like your memory or thinking skills have got worse recently?”)

155 (Barnes et al., 2013). Subjective cognitive complaints are defined as a subjective perception of 156 cognitive deterioration by an individual or their peers, even though the individual may seem to

157 perform well in neuropsychological tests, and may not demonstrate signs of objective cognitive 158 impairment (Amariglio et al., 2012; Chao et al., 2010; Jessen et al., 2010). As well, we included 159 individuals who were fully independent in functional activities (maximum score in the Lawton160 Brody Instrumental Activities of Daily Living scale [8/8]) (Lawton and Brody, 1969).

161 Individuals were excluded if they self-reported a diagnosis of dementia and/or scored $<24$ on the 162 Mini-Mental State Examination (MMSE) (Folstein et al., 1975), had major depression, recent 163 history of severe cardiovascular conditions, any neurological and/or psychiatric disorders, or 164 were unable to comprehend the study letter of information.

165 The study was registered with ClinicalTrials.gov on 29 April 2014 (Identifier: NCT02136368).

166 The Western University Health Sciences Research Ethics Board approved this project and all 167 participants provided written informed consent prior to taking part in the study.

\subsection{Multiple-modality exercise intervention}

169 Participants in both groups received 45 minutes of group-based, standardized, multiple-modality 170 exercise, described in detail elsewhere (Gregory et al., 2016). The M4 group performed an 171 additional 15 minutes of mind-motor training (i.e., SSE), whereas the M2 group underwent 15 172 minutes of training focused on balance, range of motion and breathing exercises (i.e., active 
173 control condition). In total, participants in both groups exercised 60 minutes/day, 3 days/week

174 for 24 weeks.

175 The multiple-modality exercise intervention incorporated a 5-minute warm-up, 20-minute

176 aerobic exercise (AE), 5-minute cool down, followed by 10 minutes of resistance training (see

177 Table e-1) and 5 minutes of stretching. AE intensity was prescribed via target heart rates (HR)

178 determined at baseline using the STEP ${ }^{\mathrm{TM}}$ tool (Stuckey et al., 2012). During the AE component,

179 participants were encouraged to keep their HR at $65-85 \%$ of their predicted maximum HR

180 (HRmax) and/or at a rating of 5-8 on the 10-point modified Borg Rating of Perceived Exertion

181 (RPE) scale (Chodzko-Zajko et al., 2009). HR monitoring was conducted part way through and

182 at the end of the AE component during each exercise session. Participants were instructed to

183 record HR and RPE immediately after each monitoring in a training log provided by the research

184 team. Target HR were recalculated at 12 weeks to adjust for progression in the AE training.

185 2.3.1. Active control intervention

186 The active control group underwent an additional 15 minutes of balance, range of motion and

187 breathing exercises, prior to the 5 minutes of stretching. This component of the intervention was

188 focused on low-intensity exercises without use of any additional loading (e.g., hand weights or

189 resistance bands), with HR maintained below target zone, and were deemed as a suitable active

190 control condition (Gregory et al., 2016). Participants performed 10 minutes of static (e.g.,

191 postures in narrow stance, tandem stance and single leg stance), dynamic (e.g., walk tandem line

192 on heels or toes) and functional balance (e.g., changing direction on cue, walking with head

193 turns). The session ended with 5 minutes of range of motion exercises (e.g., shoulder, hip and

194 wrist circles) and accompanied by either standing or sitting breathing exercises. 


\subsubsection{Mind-motor training intervention}

196 In addition to the multiple-modality exercise intervention, participants within the M4 group also

197 performed SSE training (Shigematsu et al., 2008a), prior to the 5 minutes of stretching. The SSE

198 program is a group-based intervention performed on a gridded floor mat $(2.5 \mathrm{~m} \times 1 \mathrm{~m})$

199 containing 10 rows with 4 equal-sized squares per row. The training protocol entails the

200 reproduction of previously demonstrated complex stepping patterns on the SSE mat (see Figure

201 1). The stepping patterns are demonstrated by an instructor and participants are expected to

202 memorize, and further attempt to reproduce each stepping pattern by memory. Instructors could

203 not physically intervene, but in instances where participants were having difficulty reproducing

204 the SSE patterns, they were provided oral cues. There are more than 200 stepping patterns

205 created for SSE (Shigematsu et al., 2008a), and the complexity of these stepping patterns is given

206 according to the number of steps per pattern, as well as the order and direction of foot placement

207 across the SSE mat. In our study, the SSE sessions were carried out in groups of no more than 6

208 participants per mat. To ensure equal group progression throughout the program, the complexity

209 of the stepping patterns within each session was increased only when the majority of participants

210 (i.e., 75\%) had successfully performed a given stepping pattern at least four times. The goal was

211 to progress through as many SSE patterns as possible over the 24-week intervention period.

212 Additionally, to create a positive social atmosphere, participants were encouraged to assist each

213 other, as necessary, by providing cues to accurately perform the stepping patterns. 

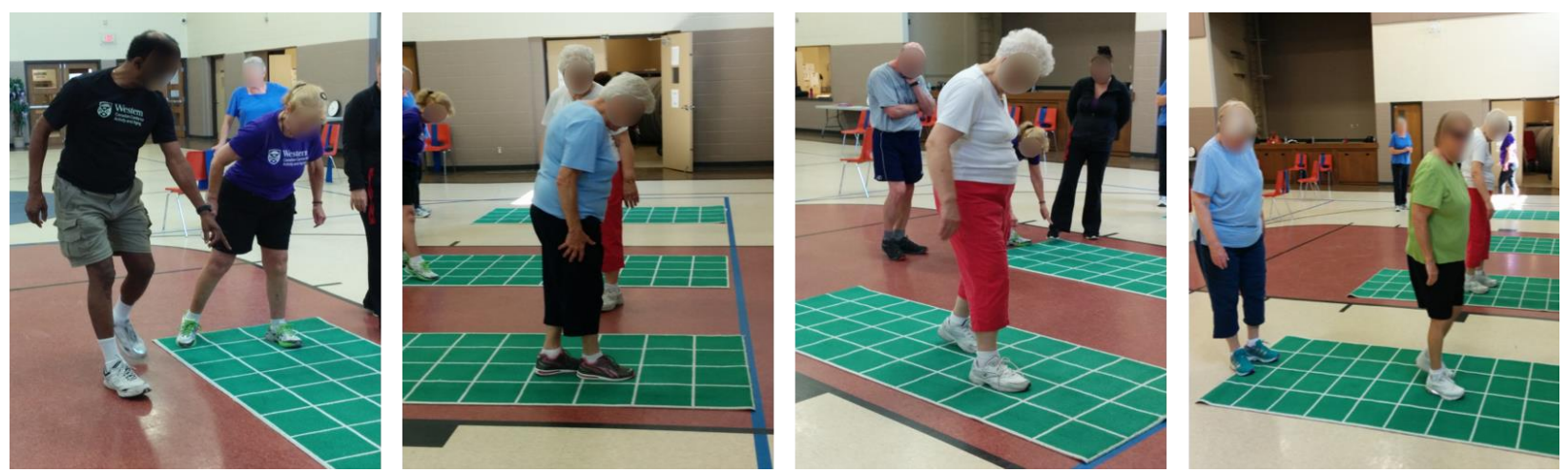

Figure 1. Participants performing stepping patterns during a square-stepping exercise session.

\subsection{Data collection}

\subsubsection{Baseline variables}

218 Baseline assessments were performed after obtaining written informed consent and prior to 219 participant randomization. Neuropsychological assessments were performed using the MMSE, 220 the Montreal Cognitive Assessment (MoCA), (Nasreddine et al., 2005) and the Centre for 221 Epidemiological Studies Depression Scale (Lewinsohn et al., 1997). Participant clinical and 222 demographic data included: age, sex, race, medical history, weight, height, body mass index 223 (BMI), and 24-hour blood pressure. Additionally, cardiorespiratory fitness was assessed at 224 baseline (predicted maximal oxygen consumption [ $\mathrm{pVO}_{2}$ max]) using the STEP tool (Stuckey et 225 al., 2012).

\subsubsection{Study outcomes}

227 The primary objective of the M4 Study was to investigate changes in global and domain-specific

228 cognitive functioning via the Cambridge Brain Sciences cognitive battery (Hampshire et al.,

229 2012), following the 24-week intervention period and a 26-week no-contact follow-up. The focus

230 of this article, however, is to report findings of our secondary outcome in which we investigated

231 changes in spatiotemporal gait characteristics. Please see Gregory et al., (2016) for further details 232 regarding the M4 Study. 
233 Spatiotemporal gait characteristics were collected using a portable electronic walkway system

234 (GAITRite ${ }^{\circledR}$ System, $580 \times 90 \times 0.63 \mathrm{~cm}(\mathrm{~L} \times \mathrm{W} \times \mathrm{H})$, scanning frequency of $60 \mathrm{~Hz}$, Software

235 Version 4.7.1, CIR Systems, Peekskill, NY, USA). The GAITRite ${ }^{\circledR}$ is valid and reliable for gait

236 assessment in various populations, including older adults with and without mobility impairment

237 (Bilney et al., 2003; Montero-Odasso et al., 2009). Participants completed two usual walking

238 trials (i.e., walking at usual pace), followed by two separated walking trials under DT conditions

239 (i.e., phonemic verbal fluency [VF] and serial sevens [S7] tasks) at a self-selected walking

240 velocity. In the DT gait VF task, participants were instructed to name as many animals

241 (baseline), vegetables (24 weeks), and countries (52 weeks) as possible. For the S7 task,

242 participants were instructed to perform subtractions by sevens starting at 100 (baseline), 90 (24

243 weeks), and 80 (52 weeks). No instructions to prioritize gait performance or responses to the

244 cognitive tasks during the DT conditions were given to the participants. In each trial, participants

245 were instructed to start walking $1 \mathrm{~m}$ before and continue to walk until $1 \mathrm{~m}$ beyond the electronic

246 walkway, in order to measure steady-state walking. Gait performance over two walking trials

247 were averaged and used for analysis. The measures of interest were usual and DT (VF and S7)

248 gait velocity $(\mathrm{cm} / \mathrm{s})$, step length $(\mathrm{cm})$, and cycle time variability (coefficient of variation [\%])

249 (Montero-Odasso et al., 2014).

250 In addition, we were interested in cognitive performance under the DT gait conditions (i.e.,

251 accuracy). As such, following previous methods (Maclean et al., 2017a), DT cognitive accuracy

252 while dual-tasking was measured based on the number of correct cognitive responses (ccr)

253 provided by each participant during the two DT gait assessments. This number was then divided

254 by the time (s) taken for each individual DT condition. To adjust for performance errors, ccr/s

255 was finally multiplied by the ratio of correct responses to total responses. We discarded repeated 
answers during each trial and did not consider answers that were deemed to be inappropriate or incorrect (e.g., naming 'cities' instead of 'countries' during the DT gait VF trial at 52 weeks).

\subsection{Sample size calculations}

259 The sample size included in this study was calculated based on the primary outcome from the

260 larger RCT (i.e., difference between groups at 24 weeks in global cognitive functioning derived

261 from the computer-based Cambridge Brain Sciences cognitive battery ) (Gregory et al., 2016;

262 Owen et al., 2010). Briefly, results from a previous meta-analysis indicated that exercise could

263 improve cognition with an moderate effect size $(d=0.48)$ (Colcombe and Kramer, 2003).

264 Although our study has a different design (e.g., intervention and outcome), we decided to take

265 this number into account. Therefore, a sample size of 52 participants per group would have an

$26680 \%$ power at the $5 \%$ significance level to detect a moderate effect size of 0.55 in cognition.

267 Considering a dropout rate of $20 \%$ during the 24 -week intervention period, our final sample size

268 was estimated at 130 participants (65 in each group). In a recent meta-analysis (Hortobágyi et al.,

269 2015), multiple-modality exercise was associated with improvements in usual gait velocity in

270 healthy older adults with an effect size of $d=.77$. Thus, if gait velocity were used to estimate the

271 study sample size as the primary outcome, considering an $80 \%$ power at $5 \%$ significance level

272 and a dropout rate of $20 \%$, we would need only 25 participants per group (50 participants in

273 overall) to detect a significant treatment effect.

\subsection{Statistical Analysis}

275 We conducted linear mixed models for repeated measurements (Fitzmaurice et al., 2011) to

276 assess differences between groups in mean change from baseline to 24 weeks. Within the

277 models, we also examined differences between groups from baseline to 52 weeks, and

278 differences within groups from baseline to 24 and 52 weeks. The terms included in the models 
were: group, time, and group $\times$ time. Time was modeled categorically using two indicator

280 variables representing each time point (baseline as reference category). All analyses were

281 performed using the intent-to-treat approach, including all randomized participants, regardless of

282 compliance with the program and follow-up assessments (Fitzmaurice et al., 2011). An

283 advantage of the mixed effects regression modeling approach is that it does not require each

284 participant to have the same number of measurements provided data are missing at random (i.e.,

285 after taking observed data into account, there are no systematic differences between participants

286 with complete data as compared to those with missing data). This is also an assumption made by

287 most multiple imputation methods (Fitzmaurice et al., 2011). We also performed a sensitivity

288 analysis including only those who completed the study assessments at all time points. As well,

289 for the main outcomes of the study, we conducted analyses adjusting for global cognitive

290 functioning at baseline (MoCA scores). Interpretation of study results were primarily based on

291 mean estimation and associated $95 \%$ confidence intervals. All analyses were performed using

292 IBM ${ }^{\circledR}$ SPSS ${ }^{\circledR}$ Statistics for Mac, Version 21 (Armonk, NY: IBM Corp).

\section{3. Results}

\subsection{Enrollment, randomization, and adherence}

295 This study was conducted between January 13, 2014 and March 14, 2016. Participants were 296 enrolled in 4 waves of assessments and intervention over a period of 14 months. During the 297 screening process, 169 individuals were assessed for eligibility; 11 did not meet the inclusion 298 criteria and 31 declined to participate. Thus, 127 participants were included and randomized to

299 either the M2 (n=64) or M4 (n=63) groups, 109 participants attended assessments at 24 weeks, 300 and 102 returned for the final assessments at 52 weeks (see Figure 2). Participants had completed 301 the study and the average attendance to the exercise sessions was $72 \%$ for the M2 group (52 out 
302 of 72 sessions) and $68 \%$ for the M4 group (49 out of out of 72 sessions). A two-sided

303 independent samples t-test revealed no significant differences between groups in participant

304 average attendance $(\mathrm{p}=.3)$. At the end of the intervention period, participants in the M4 group

305 had achieved the Advanced Level 3 of the SSE program, with stepping patterns ranging from 12

306 to 16 steps, and with steps performed in a broader range of directions (backwards, diagonal, and

307 backwards diagonal), as well as with stepping patterns incorporating wider and longer steps (3 to

3085 squares between feet). Considering attendance level and program achievement, the SSE

309 program was shown to be feasible in this specific population (i.e., older adults with SCC) and no

310 study-related adverse events were recorded.

311 Table 1 provides the baseline descriptive characteristics of the 127 participants. In overall, the

312 study participants were mostly Caucasian, highly educated and presented with sings of cognitive

313 deterioration based on mean MoCA scores. Further observation of the domain-specific MoCA

314 scores revealed that participants in both groups showed low scores in the delayed-recall memory

315 composite, which indicate memory loss possibly underlying the nature of the self-reported SCC.

316 As well, even though participants involved in the study were high-functioning and lived

317 independently in the community, $\mathrm{pVO}_{2} \max$ assessment yielded classification of 'poor' to 'fait'

318 cardiorespiratory fitness compared to age and gender reference values (Heyward and Gibson,

319 2014).The study outcomes at baseline are presented in Table 2, participants demonstrated high

320 gait velocity and low cycle time variability for age, indicating preserved function (Studenski et

321 al., 2011). 


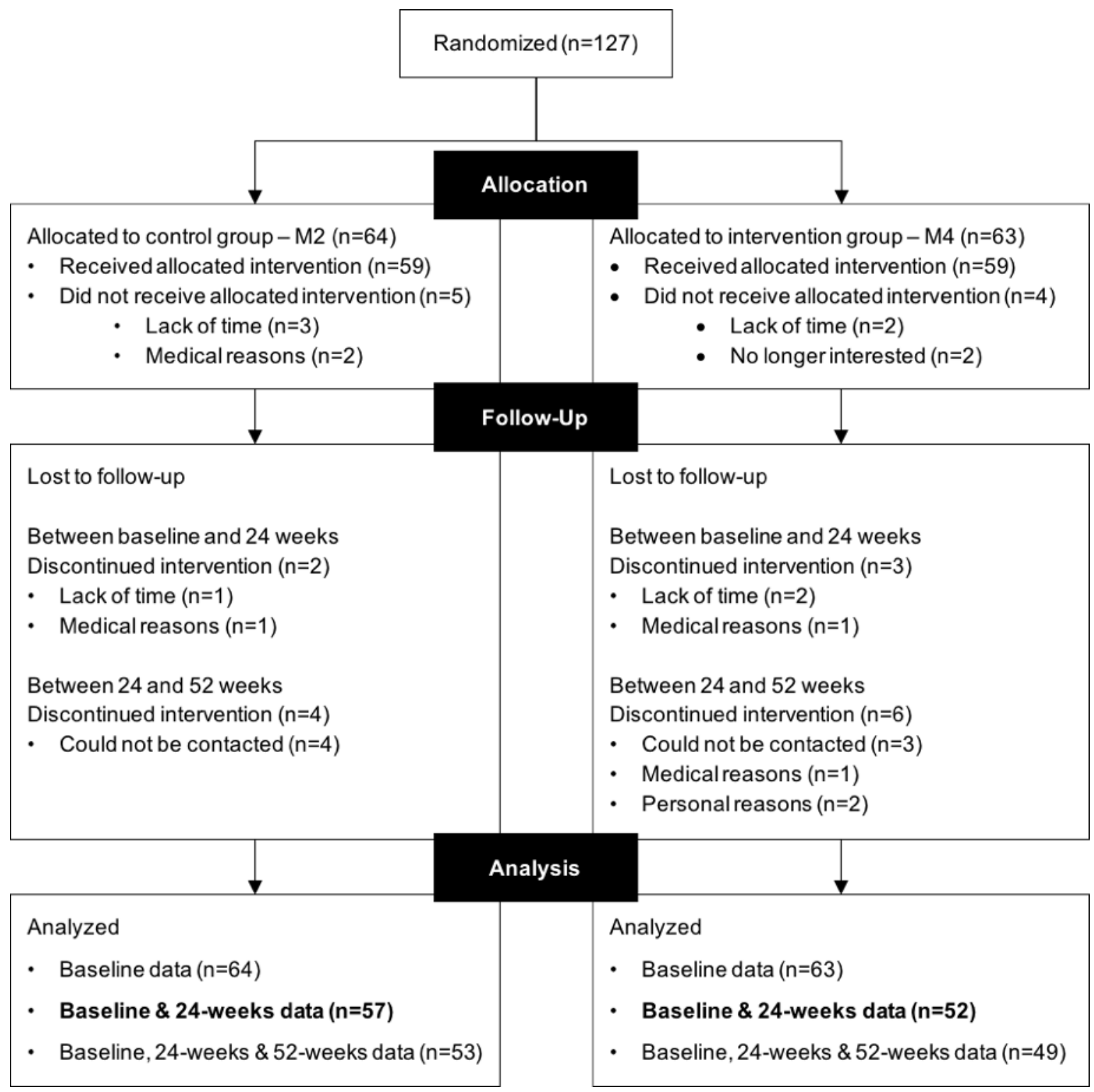

Figure 2. Flow of participant in the 24-week randomized controlled trial with a 28 -week no-contact follow-up. For

324 the M4 group, data from 4 participants were missing at 24 weeks and, therefore, not included in analyses. 
325 Table 1. Baseline demographics and clinical characteristics.

\begin{tabular}{|c|c|c|}
\hline Variables ${ }^{a, b}$ & M2 $(n=64)$ & $\mathrm{M} 4(\mathrm{n}=63)$ \\
\hline \multicolumn{3}{|l|}{ Demographics } \\
\hline Age, yr & $67.4(7.2)$ & $67.6(7.5)$ \\
\hline Females & $46(71.9 \%)$ & $44(69.8 \%)$ \\
\hline Caucasian & $62(98.4)$ & $61(96.8)$ \\
\hline Education, yr & $13.8(3)$ & $13.3(2.7)$ \\
\hline $\operatorname{MoCA}$, score $(/ 30)^{c}$ & $25.6(2.4)$ & $25.3(2.7)$ \\
\hline Visuospatial/Executive ( /5) & $4(2)$ & $4(2)$ \\
\hline Naming ( /3) & $3(0)$ & $3(0)$ \\
\hline Attention ( /6) & $6(1)$ & $6(1)$ \\
\hline Language ( /3) & $3(0)$ & $3(0)$ \\
\hline Abstraction ( /2) & $2(0)$ & $2(0)$ \\
\hline Delayed recall ( /5) & $3(2)$ & $3(2)$ \\
\hline Orientation ( /6) & $6(0)$ & $6(0)$ \\
\hline$\leq 12$ years of education & $19(30 \%)$ & $15(24 \%)$ \\
\hline MMSE, score & $29.2(1)$ & $29(1.2)$ \\
\hline CES-D, score & $9.4(7.4)$ & $10(8.9)$ \\
\hline 24-hour systolic BP, mmHg & $129.6(15.2)$ & $126.5(11.3)$ \\
\hline 24-hour diastolic BP, $\mathrm{mmHg}$ & $74.2(8.3)$ & $72.2(8.1)$ \\
\hline Weight, kg & $80.8(17.7)$ & $80(13.8)$ \\
\hline Height, $\mathrm{m}$ & $1.65(0.1)$ & $1.65(0.1)$ \\
\hline BMI, $\mathrm{kg} / \mathrm{m}^{2}$ & $29.7(6.2)$ & $29(4.1)$ \\
\hline $\mathrm{pVO}_{2} \max , \mathrm{ml} / \mathrm{kg} / \mathrm{min}$ & $26.8(8)$ & $27.1(7.9)$ \\
\hline \multicolumn{3}{|l|}{ Medical history, $n(\%)$} \\
\hline Hypertension & $32(50 \%)$ & $36(57.1 \%)$ \\
\hline Hypercholesterolemia & $23(35.9 \%)$ & $28(44.4 \%)$ \\
\hline Type 2 diabetes & $5(7.8 \%)$ & $7(11.1 \%)$ \\
\hline Myocardial infarction & $4(6.3 \%)$ & $5(7.9 \%)$ \\
\hline Atrial fibrillation & - & $3(4.8 \%)$ \\
\hline Angina/coronary artery disease & $1(1.6 \%)$ & $2(3.2 \%)$ \\
\hline Aneurysm & $1(1.6 \%)$ & $2(3.2 \%)$ \\
\hline Former smoker & $28(44.4 \%)$ & $29(46 \%)$ \\
\hline Current smoker & $1(1.6 \%)$ & $1(1.6 \%)$ \\
\hline
\end{tabular}

Abbreviations: M2, multiple-modality group; M4, multiple-modality, mind-motor group; MMSE, Mini-Mental

327 Status Examination; MoCA, Montreal Cognitive Assessment; CES-D, Centre for Epidemiological Studies

328 Depression Scale; BP, blood pressure; $\mathrm{pVO}_{2} \max$, predicted maximal oxygen consumption. 
$329{ }^{a}$ Data presented either as mean (standard deviation) or no. (\%) where applicable.

$330 \quad{ }^{\mathrm{b}}$ There were no differences between groups in any of the baseline measurements.

$331{ }^{\mathrm{c}}$ Domain-specific MoCA scores presented as median and interquartile range. 


\section{Table 2. Baseline study outcomes}

\begin{tabular}{lcc}
\hline Outcomes $^{\text {a,b }}$ & M2 (n=64) & M4 (n=63) \\
\hline Usual gait & $116.5(16.7)$ & $116.6(20.9)$ \\
$\quad$ Gait velocity, cm/s & $64.7(7.9)$ & $64.03(9.8)$ \\
$\quad$ Step length, cm & $1.8(1.5,2.3)$ & $2.08(1.5,2.8)$ \\
$\quad$ Cycle time variability, \%, Mdn (IQR) & & \\
DT Gait (VF) & $97.6(23.5)$ & $94.6(26.7)$ \\
$\quad$ Gait velocity, cm/s & $61.2(8.7)$ & $59.7(10.8)$ \\
Step length, cm & $3.8(2.3,7)$ & $4(2.1,8.1)$ \\
$\quad$ Cycle time variability, \%, Mdn (IQR) & & \\
DT Gait (S7) & $88.9(26.7)$ & $85.4(28.2)$ \\
$\quad$ Gait velocity, cm/s & $59.9(10.2)$ & $58.4(10.6)$ \\
Step length, cm & $5(2.7,8.1)$ & $4.6(3,7.1)$ \\
Cycle time variability, \%, Mdn (IQR) & & \\
Secondary outcomes & $1.16(.33)$ & $1.02(.33)$ \\
$\quad$ DT cognitive accuracy (VF), ccr/s & $.40(.35)$ & $.37(.36)$ \\
DT cognitive accuracy (S7), ccr/s & .
\end{tabular}

Abbreviations: M2, multiple-modality group; M4, multiple-modality, mind-motor group; Mdn, median; IQR,

334 interquartile range, VF, verbal fluency task; S7, serial sevens task; CCR, rate of correct cognitive responses.

$335 \quad{ }^{a}$ Data presented as mean (standard deviation) or otherwise indicated.

$336{ }^{\mathrm{b}}$ There were no differences between groups at baseline in any of the study outcomes.

\subsection{Study outcomes}

339 Table 3 shows differences between groups in estimated mean change from baseline to 24 and 52

340 weeks in the study outcomes. At 24 weeks, the M4 group demonstrated inferior performance in

341 usual gait velocity, usual step length, and DT gait velocity (VF) compared to the M2 group.

342 Differences between groups in usual gait velocity remained significant and 52 weeks, favouring

343 the M2 group. No other differences were seen in the remaining outcomes; however, the M4

344 group demonstrated a trend for higher DT cycle time variability $(\mathrm{VF})$ at 24 weeks $(\mathrm{p}=.054)$

345 compared to the M2 group. 
346 Regarding within-group analyses, Figure 3 shows the estimated mean change from baseline to 24

347 and 52 weeks. At 24 weeks, improvements were observed in usual gait velocity and usual step

348 length among participants in the M2 group; whereas the M4 group demonstrated decline in DT

349 step length (VF) at the same time point. Lastly, the M4 group demonstrated a trend for increased

350 DT cognitive accuracy (VF) at 52 weeks $(\mathrm{p}=.052)$.

351 In addition, the sensitivity analysis, which included only participants who completed the study,

352 did not change the main findings, except that it confirmed the trend for increased DT cycle time

353 variability $(\mathrm{VF})$ at 24 weeks $(\mathrm{p}=.049)$ in the M4 group compared to the M2 group (see

354 Supplemental Table 1). As well, there results remained the same when adjusting for global

355 cognitive functioning at baseline (MoCA scores).

356 Table 3. Differences between groups in the study outcomes

\begin{tabular}{|c|c|c|c|c|c|c|}
\hline \multirow{2}{*}{$\frac{\text { Outcomes }^{\text {b }}}{\text { Usual gait }}$} & \multicolumn{6}{|c|}{ Difference between groups in estimated mean change $(95 \% \mathrm{CI})^{a}$} \\
\hline & 24 weeks & \multicolumn{2}{|c|}{$p$ Values } & 52 weeks & \multicolumn{2}{|c|}{$p$ Values } \\
\hline Gait velocity, $\mathrm{cm} / \mathrm{s}$ & $\begin{array}{c}-10.1(-15.8 \text { to }- \\
4.4)\end{array}$ & $<.001 *$ & $.001 * *$ & $\begin{array}{c}-6.7(-13.4 \text { to }- \\
.05)\end{array}$ & $.048^{*}$ & $.044 * *$ \\
\hline Step length, $\mathrm{cm}$ & $-2.9(-4.8$ to -1$)$ & $.003^{*}$ & $.003 * *$ & $-2.1(-4.2$ to .1$)$ & .06 & $.06 * *$ \\
\hline Cycle time variability, $\%^{c}$ & $.02(-.08$ to .11$)$ & .74 & .72 & $-.01(-.11$ to .09$)$ & .86 & .89 \\
\hline \multicolumn{7}{|l|}{ Dual-task gait (VF) } \\
\hline Gait velocity, $\mathrm{cm} / \mathrm{s}$ & $-7.9(-15.5$ to -.3$)$ & $.043^{*}$ & $.039 * *$ & $-4.8(-14.7$ to 5$)$ & .33 & .32 \\
\hline Step length, cm & $-1.8(-4$ to .5$)$ & .11 & .11 & $-.4(-3$ to 2.2$)$ & .76 & .74 \\
\hline Cycle time variability, $\%^{c}$ & $.15(-.002$ to .29$)$ & .054 & .052 & $.11(-.06$ to .27$)$ & .19 & .18 \\
\hline \multicolumn{7}{|l|}{ DT gait (S7) } \\
\hline Gait velocity, $\mathrm{cm} / \mathrm{s}$ & $-7.3(-15.9$ to 1.2$)$ & .09 & .085 & $-7.5(-17$ to 1.9$)$ & .11 & .11 \\
\hline Step length, cm & $-1.5(-4$ to 1$)$ & .23 & .22 & $-2.2(-4.7$ to .3$)$ & .09 & .085 \\
\hline Cycle time variability, $\%^{\mathrm{c}}$ & $.11(-.05$ to .27$)$ & .17 & .15 & $.1(-.07$ to .27$)$ & .23 & .21 \\
\hline \multicolumn{7}{|l|}{ Secondary outcomes } \\
\hline DT cognitive accuracy $(\mathrm{VF}), \mathrm{ccr} / \mathrm{s}^{\mathrm{d}}$ & $-.05(-.23$ to .14$)$ & .62 & .58 & $.13(-.04$ to .31$)$ & .14 & .16 \\
\hline DT cognitive accuracy (S7), ccr/s ${ }^{\mathrm{d}}$ & $-.04(-.22$ to .13$)$ & .62 & .64 & $.02(-.16$ to 19$)$ & .86 & .84 \\
\hline
\end{tabular}


358 Abbreviations: 95\% CI, confidence interval; M2, multiple-modality group; M4, multiple-modality, mind-motor group; DT, dual-task; VF, verbal fluency task; S7, serial sevens task; CCR, rate of correct cognitive response.

${ }^{a}$ Calculated from linear mixed effects regression models that included group (M2 or M4), time (baseline, 24 and 52

361 weeks), and group $\times$ time interaction terms. A total of 13 models were conducted, corresponding to each outcome

362 listed in the first column.

$363{ }^{\mathrm{b}}$ M4 group: baseline, $\mathrm{n}=63 ; 24$ weeks, $\mathrm{n}=52 ; 52$ weeks, $\mathrm{n}=49$. M2 group: baseline, $\mathrm{n}=64 ; 24$ weeks, $\mathrm{n}=57 ; 52$

364 weeks, $\mathrm{n}=53$.

$365{ }^{\mathrm{c}}$ Log transformation applied.

$366{ }^{\mathrm{d}}$ Square root transformation applied.

$367 *$ Significant differences between groups in estimated mean change from baseline.

$368 * *$ Significant differences between groups in estimated mean change from baseline adjusted for MoCA scores.

A. Usual gait velocity
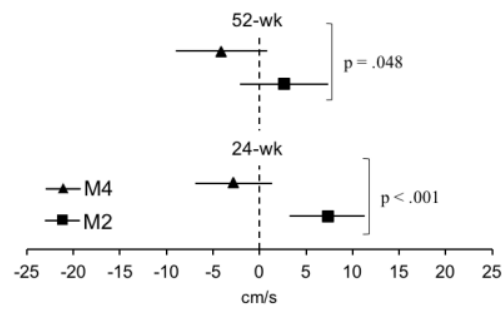

D. Dual-task gait velocity (VF)

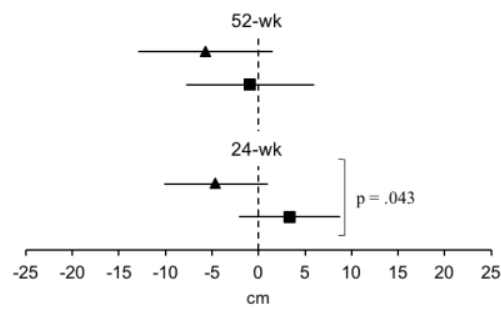

G. Dual-task gait velocity (S7)
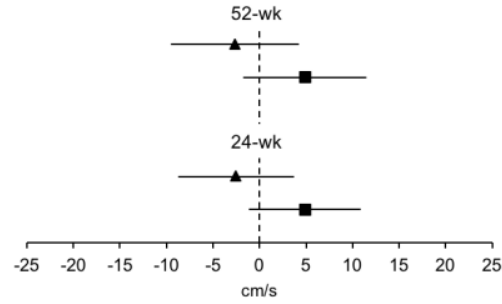

B. Usual step length

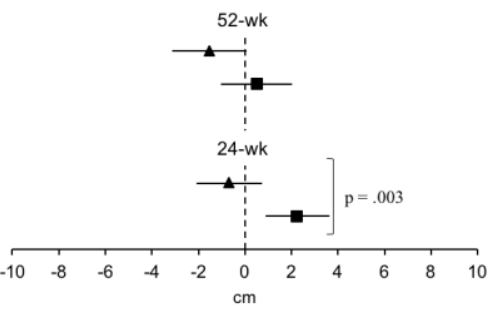

E. Dual-task step length (VF)

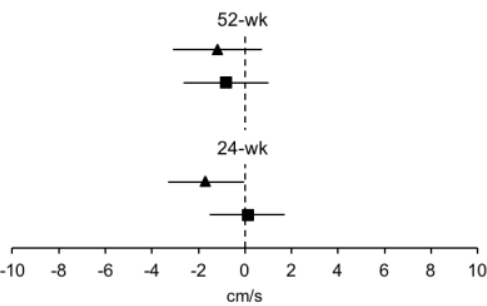

H. Dual-task step length (S7)

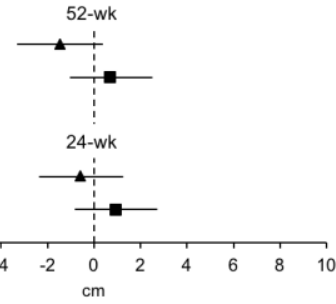

C. Usual cycle time variability

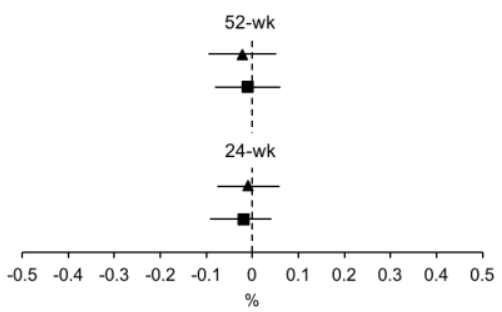

F. Dual-task cycle time variability (VF)

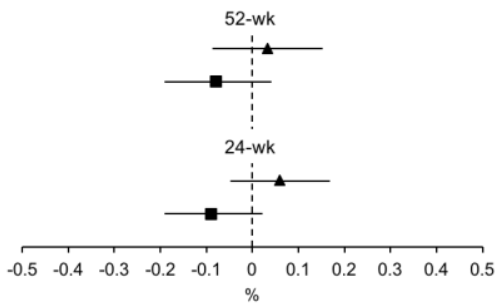

I. Dual-task cycle time variability (S7)

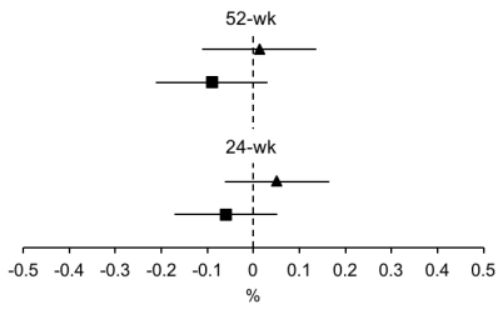


371 Figure 3. Within-group estimated mean changes from baseline in the study primary outcomes. Solid squares (M2)

372 and triagles (M4) represent point estimated group mean change from baseline; bars represent associated 95\%

373 confidance intervals. Confidence intervals not including zero (i.e., not crossing the vertical dotted line) indicate

374 significant differences from baseline. $\mathrm{P}$ value indicates significant differences between groups in estimated mean

375 change from baseline (see supplemental table 2 for specific). Abbreviations: M2, multiple-modality group; M4,

376 multiple-modality, mind-motor group. 24-wk, intervention endpoint; 52-wk, study endpoint

\section{4. Discussion}

378 The results of the current study indicated that the addition of mind-motor training (i.e., SSE) to a 379 standardized multiple-modality exercise intervention did not yield further improvements in 380 spatiotemporal gait characteristics and DT cognitive accuracy. Nonetheless, the multiple381 modality exercise intervention with additional balance, range of motion and breathing exercises 382 (i.e., M2) did impart improvements to usual gait velocity, step length, and DT gait velocity (VF) 383 at 24 weeks, and did retain the gains in usual gait velocity at 52 weeks. The changes observed in 384 the M2 group are in accordance with previous investigations (Hortobágyi et al., 2015; Plummer 385 et al., 2015). Results from a systematic review and meta-analysis indicated that multiple386 modality exercise interventions may yield clinically significant changes in gait velocity in older 387 adults (mean change $0.09 \mathrm{~m} / \mathrm{s}$ or $8.4 \%$ ) similar to our findings $(0.07 \mathrm{~m} / \mathrm{s}$ or $6.25 \%$ ) (Hortobágyi 388 et al., 2015).

389 A surprising finding of the current study is that despite the fact that SSE was developed to 390 promote improvements in lower extremity functioning in at-risk older fallers (Shigematsu et al., 391 2008a), it did not provide additional benefits to gait performance when added to the M2 exercise 392 component. From a neuromuscular point of view, the lack of improvement within the M4 group 393 may indicate that the specific biomechanical and/or physical requirements of SSE are not 394 intrinsically associated with the mechanisms underlying exercise-induced changes in gait 
dynamics in older adults (Hausdorff et al., 2001a). Further, the fact that M2 group received

396 additional balance exercises may account for the superior gait performance in comparison to the

397 M4 group. Indeed, positive changes in gait performance following balance training in older

398 adults have been widely reported in the literature (Hortobágyi et al., 2015), and have been

399 associated with reduced risk for mobility impairment and falls (Sherrington et al., 2011). Taking

400 this perspective, even though previous studies (Shigematsu et al., 2008a, 2008b; Shigematsu and

401 Okura, 2006) indicated that SSE improved balance in older adults-which was the basis of our

402 hypothesis that SSE would impart similar or greater benefits than the additional balance

403 exercises-we failed to report such improvements.

404 It is important to mention, however, that the SSE program encompasses gradual progression in

405 complexity to perform the stepping patterns; this complexity is determined by the number of

406 steps performed, as well as the direction and length of the steps. Therefore, at a certain point in

407 the program (advanced phase), participants did perform stepping patterns requiring wider and

408 lengthier steps and thus, improvements in spatiotemporal gait characteristics could be expected.

409 As the key component of SSE is its simultaneous cognitive-physical demand, we argue that it

410 was a valid hypothesis to expect favourable changes in the study outcomes, particularly with

411 regards to DT gait measures.

412 In addition, it was hypothesized that the specific requirements of the SSE exercise would not

413 directly train the specific gait outcomes that were considered for this study, but would act more

414 specifically to train the control of gait on a more global scale. Among healthy populations, the

415 control of gait is rather automatic and very little attention and/or effort is needed for habitual

416 daily ambulation (Woollacott and Shumway-Cook, 2002). However, the SSE removes the

417 habitual automatic walking response, and forces participants to actively modify their gait to 
418 successfully complete the task. This active modification of gait was also thought to be the key to

419 the potential effectiveness of the SSE among relatively pre-clinical patient populations; a

420 conscious modification of gait would potentially serve to strengthen the neural control of global

421 gait performance.

422 Exercise-induced improvements in gait performance are primarily attributed to gains in muscle

423 strength and neuromuscular control of the lower extremities (Hausdorff, 2005; Hausdorff et al.,

424 2001a, 2001b; Zhuang et al., 2014), especially with respect to gait velocity (Hortobágyi et al.,

425 2015). For instance, gains in gait velocity over a 22-week exercise intervention program were

426 associated with increased muscle strength in the hip flexors and ankle dorsiflexors muscles (Lord

427 et al., 1996). In the SSE sessions, the main goal was to complete the stepping pattern accurately,

428 however, time to complete the tasks was not a main priority of the program. In this scenario,

429 participants were expected to observe and retain information about the stepping patterns, then

430 proceed to their execution in order to maintain forward gait, at a relatively slow gait velocity,

431 regardless of participants' individual abilities. This may be understood as a lower-intensity set of

432 stimuli that did not reach the threshold to impart muscle adaptions and induce gains in gait

433 performance compared to the M2 group, which received additional balance exercises.

434 Additionally, the SSE stepping patterns were executed in a way that does not necessarily

435 correspond to the configuration of normal walking (e.g., backwards, lateral, and diagonal steps)

436 and may have negatively influenced the results within the M4 group, ultimately indicating task-

437 specific effects of the SSE intervention unrelated to normal walking.

438 Looking at our findings from a neurological/cognitive perspective, it was also expected that SSE

439 would improve DT gait parameters to a greater extent in the M4 group compared to the M2

440 group. Previous studies reported that SSE has been associated with improvements in EF 
441 subdomains (i.e., attention and mental flexibility) (Shigematsu, 2014; Teixeira et al., 2013),

442 which are understood as primary cognitive functions and/or brain networks involved in DT gait

443 functioning (Yogev-Seligmann et al., 2008). Therefore, it was believed that even though SSE is

444 of lower physical intensity, it would enhance DT gait parameters by benefiting EF, via a more

445 neurological/cognitive pathway as opposed to a neuromuscular pathway, due to its high

446 cognitive demand. In reality, we observed that the M4 group showed a decay in one of the DT

447 gait velocity (VF) outcomes after the intervention, which leaded to statistically significant

448 differences between groups at 24 weeks.

449 Given that no changes in any other DT gait parameters (under either VF or S7 conditions) were 450 noted, it is possible that this singular between-group difference in DT gait velocity (VF) could be

451 explained by the same neuromuscular mechanisms described previously. That is, participants had 452 slower DT gait velocity (VF) probably due the lack of an overall effect of SSE on gait, and thus, 453 the DT component did not change that relationship. If SSE had a negative effect on the cognitive 454 aspect of the DT, it would have likely appeared in the other DT gait parameters, particularly 455 under the serial sevens condition (S7), since this task has been shown to be more cognitively 456 demanding than the VF task (Li et al., 2014). Furthermore, the measures of cognitive accuracy 457 recorded from both DT gait VF and S7 conditions did not differ between groups at 24 weeks, 458 which supports this hypothesis.

459 Nonetheless, we observed a trend for increased DT cycle time variability (VF) in the M4 group 460 that is worth discussing. Increased variability in gait parameters may indicative of impairment in 461 cognitive control of gait, particularly EF (Springer et al., 2006), and has been associated with 462 increased risk of falling (Hausdorff, 2005). Although this finding may indicate an adverse effect 463 of SSE in the M4 group, it should be interpreted with caution. We did not measure EF in the 
464 current study, therefore it is unknown whether adverse changes in DT cycle time variability was

465 associated with unfavorable changes in EF. Nonetheless, this assumption is unlikely given that

466 SSE has been associated with improve EF in previous studies (Shigematsu, 2014; Teixeira et al.,

467 2013). Rather, we argue that because of the above describe characteristics of the SSE program,

468 increased gait variably would likely result from a more cautious gait pattern developed in

469 response to performing stepping patterns requiring increased attention and concentration. In fact,

470 increased gait variability is a marker of cautious gait in fallers (Herman et al., 2005). It is

471 paramount, however, to bear in mind that the trends for increased DT cycle time variability were

472 nonexistent at 52 weeks, suggesting that, if any, the adverse effects of SSE on gait variability

473 would not permanent and would wear off after program session.

474 After the no-contact follow-up period, the M4 group demonstrated trends for improvements in

475 DT cognitive accuracy (VF); this was not seen in the M2 group. Aerobic-based and multiple-

476 modality exercise interventions have been shown to improve VF in this population under single

477 task conditions (Baker et al., 2010; Suzuki et al., 2012); however, under DT conditions, exercise-

478 induced changes in DT cognitive accuracy has not been fully explored. Thus, the trend for

479 improved performance of the M4 group in the VF task may be indicative of delayed-treatment

480 impact of the exercise intervention with additional SSE (Teixeira et al., 2013), although this

481 requires further exploration particularly with regards to clinical meaningfulness of these

482 measures. This finding would implicate superior efficiency in proper allocation of attention

483 resources to the cognitive task while maintaining stable gait velocity, which may be an

484 encouraging sign of improvements in EF, particularly in our sample of older adults with SCC

485 (Maclean et al., 2017b). 
In sum, we speculate that the lack of SSE superior effects to drive between-group differences in

487 DT gait parameters may be due to two main reasons: 1) the short duration and different

488 frequency in which the mind-motor component was administered compared to previous studies

489 (Gill et al., 2016; Teixeira et al., 2013), along with the low-intensity aspect of the SSE

490 component; and 2) SSE could target specific cognitive functions/brain networks different from

491 those required under DT gait conditions and, therefore, a significant treatment effect could not be

492 expected under these circumstances. Another relevant factor to be taken into account when

493 interpreting our findings is participants' baseline characteristics. This is particularly important

494 given that participant health and functional status prior to the beginning of any given exercise

495 regimen can mediate the effect of exercise on gait performance (Hortobágyi et al., 2015). For

496 instance, in a study including patients with objective cognitive impairment, poorer baseline

497 motor performance was the only factor related to greater response to the exercise training (Hauer

498 et al., 2012). In this study, we recruited high-functioning community-dwelling older adults who,

499 despite reporting signs of early cognitive deterioration (i.e., SCC), already presented relatively

500 higher gait velocity and lower gait variability before the program, compared to population

501 parameters (Studenski et al., 2011). Consequently, the lack of improvement in the M4 group may

502 also be due the high-functioning aspect of our sample that would limit the extent to which the

503 relatively low-intensity SSE would impart additional benefits to gait performance (Hausdorff et

504 al., 2001a; You et al., 2009). In other words, this could indicate a dose-response relationship,

505 where a higher-intensity intervention would be necessary to observe significant changes in gait

506 parameters in high-functioning older adults, even in those with SCC (Hortobágyi et al., 2015;

507 Lopopolo et al., 2006). Moreover, past studies have shown that higher intensities of AE may

508 yield functional and morphological alterations in brain regions associated with the cognitive 
509 control of gait (Berchicci et al., 2013) and improve usual gait and DT gait performance (Iuliano

510 et al., 2015; Snowden et al., 2011).

511 This study presents several limitations. The lack of a non-exercising control group impaired our

512 ability to control for the possible influence of external factors. Further, limitations regarding the

513 DT assessments are also noted, including: 1) the task performance was not randomized (i.e.,

514 usual gait followed by DT gait VF, and then DT gait S7); 2) performance on the secondary

515 cognitive tasks within the DT gait evaluation was not methodologically controlled (i.e., VF and

516 S7 tasks isolated, without the walking task). Thus, our ability to determine whether changes in

517 DT gait performance were similar to change in cognitive task (isolated VF and S7 tasks) is

518 limited. In addition, AE intensity was controlled based on participants indirectly monitoring their

519 own HR (i.e., via radial artery pulse), which could have created room for underestimations and

520 participants may have exercised at different intensities from what was prescribed. In addition,

521 due to our group-based intervention, we were not able to monitor progression in both exercise

522 groups to an individual level; therefore, it cannot be concluded with high confidence that each

523 individual performed at their optimal performance. Finally, individuals in this study were

524 predominantly Caucasian, well educated, functionally independent, and relatively healthy; thus,

525 results may not be generalized to other populations.

\section{5. Conclusions}

527 The current investigation explored the influence of multiple-modality exercise with either

528 additional mind-motor training or an active control intervention (e.g., additional balance, range

529 of motion and breathing exercise) on mobility outcomes in older adults with SCC. Our findings

530 demonstrated that additional SSE training was not effective to improve usual and DT

531 spatiotemporal gait characteristics compared an active control intervention. In fact, participants 
532 enrolled in the active control group experienced greater changes in usual gait velocity, step

533 length and DT gait velocity after the 24-week intervention program.

\section{Funding}

535 This study was supported by an operating grant from the Canadian Institutes of Health Research

536 (grant number: MOP 130474), St. Joseph's Health Care Foundation (grant number: 048-1415),

537 and the Mitacs Globalink Graduate Fellowship. The funding sources for this study had no

538 involvement in study design or in the collection, analysis or interpretation of data.

\section{Acknowledgments}

540 Graduate students and Research Assistants: Erin Shellington, Ashleigh De Cruz, Joe Decaria,

541 Amanda Deosaran, Noah Koblinsky, Sam Titheridge, and Melanie Stuckey. Seniors' Fitness

542 Instructor Team: Beth Munro, Sylvia Smith, Nancy Scott, Lacy Bertin and other volunteers from

543 South Gate Centre for Active Adults 50+ in Woodstock, ON, Canada. Community partners in

544 Woodstock: South Gate Centre for Active Adults 50+ (Executive Director: Chris Cunningham);

545 Woodstock Health \& Fitness (President: Kapil Verma); Maranatha Christian Reformed Church

546 where the training sessions were done; and Salvation Army Community Church where

547 assessments were done. We would also like to thank the reviewers of this manuscript for their

548 thoughtful and extremely helpful comments and suggestions.

\section{References}

550 Allali, G., Ayers, E.I., Verghese, J., 2016. Motoric Cognitive Risk Syndrome Subtypes and

551 Cognitive Profiles. Journals Gerontol. Ser. A Biol. Sci. Med. Sci. 71, 378-384.

552 doi:10.1093/gerona/glv092

553 Allali, G., Dubois, B., Assal, F., Lallart, E., De Souza, L.C., Bertoux, M., Annweiler, C., 
Herrmann, F.R., Levy, R., Beauchet, O., 2010. Frontotemporal dementia: Pathology of gait? Mov. Disord. 25, 731-737. doi:10.1002/mds.22927

Allali, G., Kressig, R.W., Assal, F., Herrmann, F.R., Dubost, V., Beauchet, O., 2007. Changes in gait while backward counting in demented older adults with frontal lobe dysfunction. Gait Posture 26, 572-576. doi:10.1016/j.gaitpost.2006.12.011

Allali, G., van der Meulen, M., Beauchet, O., Rieger, S.W., Vuilleumier, P., Assal, F., 2013. The Neural Basis of Age-Related Changes in Motor Imagery of Gait: An fMRI Study. J. Gerontol. A. Biol. Sci. Med. Sci. 69, 1-10. doi:10.1093/gerona/glt207

Amariglio, R.E., Becker, J.A., Carmasin, J., Wadsworth, L.P., Lorius, N., Sullivan, C., Maye, J.E., Gidicsin, C., Pepin, L.C., Sperling, R.A., Johnson, K.A., Rentz, D.M., 2012. Subjective cognitive complaints and amyloid burden in cognitively normal older individuals. Neuropsychologia 50, 2880-2886. doi:10.1016/j.neuropsychologia.2012.08.011

Amariglio, R.E., Townsend, M.K., Grodstein, F., Sperling, R.A., Rentz, D.M., 2011. Specific subjective memory complaints in older persons may indicate poor cognitive function. J. Am. Geriatr. Soc. 59, 1612-1617. doi:10.1111/j.1532-5415.2011.03543.x

Baker, L.D.L., Frank, L.L.L., Foster-Schubert, K., Green, P.S., Wilkinson, C.W., McTiernan, A., Plymate, S.R., Fishel, M.A., Watson, G.S., Cholerton, B.A., Duncan, G.E., Mehta, P.D., Craft, S., 2010. Effects of aerobic exercise on mild cognitive impairment: a controlled trial. Arch. Neurol. 67, 71-79. doi:10.1001/archneurol.2009.307

Barnes, D.E., Santos-Modesitt, W., Poelke, G., Kramer, A.F., Castro, C., Middleton, L.E., Yaffe, K., 2013. The Mental Activity and eXercise (MAX) trial: a randomized controlled trial to enhance cognitive function in older adults. JAMA Intern Med 173, 797-804. 
doi:10.1001/jamainternmed.2013.189

577

578

579

580

581

582

583

584

585

586

587

588

589

590

591

592

593

594

595

596

597

Beauchet, O., Allali, G., Annweiler, C., Bridenbaugh, S., Assal, F., Kressig, R.W., Herrmann, F.R., 2009. Gait variability among healthy adults: Low and high stride-to-stride variability are both a reflection of gait stability. Gerontology 55, 702-706. doi:10.1159/000235905

Beauchet, O., Launay, C., Annweiler, C., Fantino, B., Allali, G., De Decker, L., 2013. Physical training-related changes in gait variability while single and dual tasking in older adults: Magnitude of gait variability at baseline matters. Eur. J. Phys. Rehabil. Med. 49, 857-864.

Berchicci, M., Lucci, G., Di Russo, F., 2013. Benefits of physical exercise on the aging brain: the role of the prefrontal cortex. J. Gerontol. A. Biol. Sci. Med. Sci. 68, 1337-41. doi:10.1093/gerona/glt094

Bilney, B., Morris, M., Webster, K., 2003. Concurrent related validity of the GAITRite walkway system for quantification of the spatial and temporal parameters of gait. Gait Posture 17, $68-74$.

Boa Sorte Silva, N.C., Gregory, M.A., Gill, D.P., Petrella, R.J., 2017. Multiple-modality exercise and mind-motor training to improve cardiovascular health and fitness in older adults at risk for cognitive impairment: A randomized controlled trial. Arch. Gerontol. Geriatr. 68, 149160. doi:10.1016/j.archger.2016.10.009

Brookmeyer, R., Johnson, E., Ziegler-Graham, K., Arrighi, H.M., 2007. Forecasting the global burden of Alzheimer's disease. Alzheimer's Dement. 3, 186-191. doi:10.1016/j.jalz.2007.04.381

Chao, L.L., Mueller, S.G., Buckley, S.T., Peek, K., Raptentsetseng, S., Elman, J., Yaffe, K., Miller, B.L., Kramer, J.H., Madison, C., Mungas, D., Schuff, N., Weiner, M.W., 2010. 
Evidence of neurodegeneration in brains of older adults who do not yet fulfill MCI criteria. Neurobiol. Aging 31, 368-377. doi:10.1016/j.neurobiolaging.2008.05.004

Chodzko-Zajko, W.J., Proctor, D.N., Fiatarone Singh, M.A., Minson, C.T., Nigg, C.R., Salem,

601 G.J., Skinner, J.S., 2009. Exercise and physical activity for older adults. Med. Sci. Sports

602 Exerc. 41, 1510-1530. doi:10.1249/MSS.0b013e3181a0c95c

Colcombe, S., Kramer, A.F., 2003. Fitness effects on the cognitive function of older adults: A meta-analytic study. Psychol. Sci. 14, 125-130. doi:10.1111/1467-9280.t01-1-01430

Demnitz, N., Esser, P., Dawes, H., Valkanova, V., Johansen-Berg, H., Ebmeier, K.P., Sexton, C., 2016. A systematic review and meta-analysis of cross-sectional studies examining the relationship between mobility and cognition in healthy older adults. Gait Posture 50, 164174. doi:10.1016/j.gaitpost.2016.08.028

Dorfman, M., Herman, T., Brozgol, M., Shema, S., Weiss, A., Hausdorff, J., Mirelman, A., 2014.

Fitzmaurice, G.M., Laird, N.M., Ware, J.H., 2011. Applied Longitudinal Analysis, 2nd ed. ed, Wiley Series in Probability and Statistics. John Wiley \& Sons, Hoboken, NJ. Idiopathic Fallers. J Neurol Phys Ther 38, 246-253. doi:10.1097/NPT.0000000000000057 doi:10.1198/jasa.2005.s24

Folstein, M.F., Folstein, S.E., McHugh, P.R., 1975. "Mini-mental state”. A practical method for grading the cognitive state of patients for the clinician. J. Psychiatr. Res. 12, 189-198. doi:10.1016/0022-3956(75)90026-6

Gill, D.P., Gregory, M.A., Zou, G., Liu-Ambrose, T., Shigematsu, R., Hachinski, V., Fitzgerald, C., Petrella, R.J., 2016. The healthy mind, healthy mobility trial: A novel exercise program 
for older adults. Med. Sci. Sports Exerc. 48, 297-306. doi:10.1249/MSS.0000000000000758

622

623

624

Gobbo, S., Bergamin, M., Sieverdes, J.C., Ermolao, A., Zaccaria, M., 2014. Effects of exercise on dual-task ability and balance in older adults: A systematic review. Arch. Gerontol. Geriatr. 58, 177-187. doi:10.1016/j.archger.2013.10.001

Gregory, M.A., Boa Sorte Silva, N.C., Gill, D.P., McGowan, C.L., Liu-Ambrose, T., Shoemaker, J.K., Hachinski, V., Holmes, J., Petrella, R.J., 2017. Combined Dual-Task Gait Training and Aerobic Exercise to Improve Cognition, Mobility, and Vascular Health in CommunityDwelling Older Adults at Risk for Future Cognitive Decline. J. Alzheimer's Dis. 57, 1-17. doi:10.3233/JAD-161240

Gregory, M.A., Gill, D.P., Petrella, R.J., 2013. Brain health and exercise in older adults. Curr. Sports Med. Rep. 12, 256-271. doi:10.1249/JSR.0b013e31829a74fd

Gregory, M.A., Gill, D.P., Shellington, E.M., Liu-Ambrose, T., Shigematsu, R., Zou, G., Shoemaker, K., Owen, A.M., Hachinski, V., Stuckey, M., Petrella, R.J., 2016. Group-based exercise and cognitive-physical training in older adults with self-reported cognitive complaints: The Multiple-Modality, Mind-Motor (M4) study protocol. BMC Geriatr. 16, 17. doi:10.1186/s12877-016-0190-9

Hampshire, A., Highfield, R.R., Parkin, B.L., Owen, A.M., 2012. Fractionating Human Intelligence. Neuron 76, 1225-1237. doi:10.1016/j.neuron.2012.06.022

Hauer, K., Schwenk, M., Zieschang, T., Essig, M., Becker, C., Oster, P., 2012. Physical training improves motor performance in people with dementia: A randomized controlled trial. J. Am. Geriatr. Soc. 60, 8-15. doi:10.1111/j.1532-5415.2011.03778.x 
642 Hausdorff, J.M., 2005. Gait variability: methods, modeling and meaning. J. Neuroeng. Rehabil. 2. doi:10.1186/1743-0003-2-19

644 Hausdorff, J.M., Nelson, M.E., Kaliton, D., Layne, J.E., Bernstein, M.J., Nuernberger, A., Singh, 645 M. a, 2001a. Etiology and modification of gait instability in older adults: a randomized controlled trial of exercise. J. Appl. Physiol. 90, 2117-2129.

647 Hausdorff, J.M., Rios, D.A., Edelberg, H.K., 2001b. Gait variability and fall risk in community648 living older adults: A 1-year prospective study. Arch. Phys. Med. Rehabil. 82, 1050-1056. doi:10.1053/apmr.2001.24893

Hausdorff, J.M., Schweiger, A., Herman, T., Yogev-Seligmann, G., Giladi, N., 2008. Dual-task decrements in gait: contributing factors among healthy older adults. J Gerontol A Biol Sci

Herman, T., Giladi, N., Gurevich, T., Hausdorff, J.M., 2005. Gait instability and fractal dynamics of older adults with a "cautious" gait: Why do certain older adults walk fearfully? Gait Posture 21, 178-185. doi:10.1016/j.gaitpost.2004.01.014

Heyward, V.H., Gibson, A.L., 2014. Advanced Fitness Assessment and Exercise Prescription, 7th ed, Burgess Publishing Company. Human Kinetics, Champaign, IL, US.

Hortobágyi, T., Lesinski, M., Gäbler, M., VanSwearingen, J.M., Malatesta, D., Granacher, U., 2015. Effects of Three Types of Exercise Interventions on Healthy Old Adults' Gait Speed: A Systematic Review and Meta-Analysis. Sport. Med. 45, 1627-1643. doi:10.1007/s40279015-0371-2 2015. Effects of different types of physical activity on the cognitive functions and attention 
in older people: A randomized controlled study. Exp. Gerontol. 70, 105-110. doi:10.1016/j.exger.2015.07.008

666

667

668

669

670

671

672

673

674

675

676

677

678

679

680

681

682

683

684

685

Jessen, F., Wiese, B., Bachmann, C., Eifflaender-Gorfer, S., 2010. Prediction of Dementia by Subjective Memory Impairment. Arch Gen Psychiatry 67, 414-422. doi:10.1001/archgenpsychiatry.2010.30.ABSTRACT

Jessen, F., Wolfsgruber, S., Wiese, B., Bickel, H., M??sch, E., Kaduszkiewicz, H., Pentzek, M., Riedel-Heller, S.G., Luck, T., Fuchs, A., Weyerer, S., Werle, J., Van Den Bussche, H., Scherer, M., Maier, W., Wagner, M., 2014. AD dementia risk in late MCI, in early MCI, and in subjective memory impairment. Alzheimer's Dement. 10, 76-83. doi:10.1016/j.jalz.2012.09.017

Kaup, A.R., Nettiksimmons, J., Leblanc, E.S., Yaffe, K., 2015. Memory complaints and risk of cognitive impairment after nearly 2 decades among older women. Neurology 85, 18521858. doi:10.1212/WNL.0000000000002153

Lawton, M.P., Brody, E.M., 1969. Assessment of Older People: Self-Maintaining and Instrumental Activities of Daily Living. Gerontologist 9, 179-186. doi:10.1093/geront/9.3_Part_1.179

Lewinsohn, P.M., Seeley, J.R., Roberts, R.E., Allen, N.B., 1997. Center for Epidemiologic Studies Depression Scale (CES-D) as a screening instrument for depression among community-residing older adults. Psychol. Aging 12, 277-87. doi:10.1037/08827974.12.2.277

Li, C., Verghese, J., Holtzer, R., 2014. A comparison of two walking while talking paradigms in aging. Gait Posture 40, 415-419. doi:10.1016/j.gaitpost.2014.05.062 
686

687

688

689

690

691

692

693

694

695

696

697

698

699

700

701

702

703

704

705

706

707

708

Livingston, G., Sommerlad, A., Orgeta, V., Costafreda, S.G., Huntley, J., Ames, D., Ballard, C., Banerjee, S., Burns, A., Cohen-Mansfield, J., Cooper, C., Fox, N., Gitlin, L.N., Howard, R., Kales, H.C., Larson, E.B., Ritchie, K., Rockwood, K., Sampson, E.L., Samus, Q., Schneider, L.S., Selbæk, G., Teri, L., Mukadam, N., 2017. Dementia prevention, intervention, and care. Lancet 6736. doi:10.1016/S0140-6736(17)31363-6

Lopopolo, R.B., Greco, M., Sullivan, D., Craik, R.L., Mangione, K.K., 2006. Effect of Therapeutic Exercise on Gait Speed in Community-Dwelling Elderly People: A Metaanalysis. Phys. Ther. 86, 520-540.

Lord, S.R., Lloyd, D.G., Nirui, M., Raymond, J., Williams, P., Stewart, R. a, 1996. The effect of exercise on gait patterns in older women: a randomized controlled trial. J. Gerontol. A. Biol. Sci. Med. Sci. 51, M64-M70. doi:10.1093/GERONA/51A.2.M64

MacDonald, S.W.S., Hundza, S., Love, J.A., DeCarlo, C.A., Halliday, D.W.R., Brewster, P.W.H., Lukyn, T. V., Camicioli, R., Dixon, R.A., 2017. Concurrent Indicators of Gait Velocity and Variability Are Associated with 25-Year Cognitive Change: A Retrospective Longitudinal Investigation. Front. Aging Neurosci. 9, 1-10. doi:10.3389/fnagi.2017.00017

Maclean, L.M., Brown, L.J.E., Khadra, H., Astell, A.J., 2017a. Observing prioritization effects on cognition and gait: The effect of increased cognitive load on cognitively healthy older adults' dual-task performance. Gait Posture 53, 139-144.

doi:10.1016/j.gaitpost.2017.01.018

Maclean, L.M., Brown, L.J.E., Khadra, H., Astell, A.J., 2017b. Observing prioritization effects on cognition and gait: The effect of increased cognitive load on cognitively healthy older adults' dual-task performance. Gait Posture 53, 139-144.

doi:10.1016/j.gaitpost.2017.01.018 
Montero-Odasso, M., Casas, A., Hansen, K.T., Bilski, P., Gutmanis, I., Wells, J.L., Borrie, M.J., 2009. Quantitative gait analysis under dual-task in older people with mild cognitive impairment: a reliability study. J. Neuroeng. Rehabil. 6, 35. doi:10.1186/1743-0003-6-35

712

713

714

715

716

Montero-Odasso, M., Muir, S.W., Speechley, M., 2012. Dual-task complexity affects gait in people with mild cognitive impairment: The interplay between gait variability, dual tasking, and risk of falls. Arch. Phys. Med. Rehabil. 93, 293-299. doi:10.1016/j.apmr.2011.08.026

Montero-Odasso, M., Oteng-Amoako, A., Speechley, M., Gopaul, K., Beauchet, O., Annweiler, C., Muir-Hunter, S.W., 2014. The motor signature of mild cognitive impairment: Results from the gait and brain study. Journals Gerontol. - Ser. A Biol. Sci. Med. Sci. 69, 14151421. doi:10.1093/gerona/glu155

Nasreddine, Z.S., Phillips, N.A., Bedirian, V., Charbonneau, S., Whitehead, V., Collin, I., Cummings, J.L., Chertkow, H., Bédirian, V., Charbonneau, S., Whitehead, V., Colllin, I., Cummings, J.L., Chertkow, H., 2005. The Montreal Cognitive Assessment, MoCA: a brief screening tool for mild cognitive impairment. J Am Geriatr Soc 53, 695-699. doi:10.1111/j.1532-5415.2005.53221.x

Owen, A.M., Hampshire, A., Grahn, J.A., Stenton, R., Dajani, S., Burns, A.S., Howard, R.J., Ballard, C.G., 2010. Putting brain training to the test. Nature 465, 775-8. doi:10.1038/nature09042

Plassman, B.L., Langa, K.M., McCammon, R.J., Fisher, G.G., Potter, G.G., Burke, J.R., Steffens, D.C., Foster, N.L., Giordani, B., Unverzagt, F.W., Welsh-Bohmer, K.A., Heeringa, S.G., Weir, D.R., Wallace, R.B., 2011. Incidence of dementia and cognitive impairment, not dementia in the united states. Ann. Neurol. 70, 418-426. doi:10.1002/ana.22362 
732 Plummer, P., Zukowski, L.A., Giuliani, C., Hall, A.M., Zurakowski, D., 2015. Effects of

733 Physical Exercise Interventions on Gait-Related Dual-Task Interference in Older Adults: A

734 Systematic Review and Meta-Analysis. Gerontology 62, 94-117. doi:10.1159/000371577

735 Prince M, Wimo A, Guerchet M, et al., 2015. World Alzheimer Report 2015: The Global Impact

736 of Dementia | Alzheimer's Disease International, Alzheimer's Disease International, 737 London.

738 Saykin, A.J., Wishart, H.A., Rabin, L.A., Santulli, R.B., Flashman, L.A., West, J.D., McHugh, 739 T.L., Mamourian, A.C., 2006. Older adults with cognitive complaints show brain atrophy 740 similar to that of amnestic MCI, Neurology. doi:10.1212/01.wnl.0000234032.77541.a2

741 Sherrington, C., Tiedemann, A., Fairhall, N., Close, J.C.T., Lord, S.R., 2011. Exercise to prevent 742 falls in older adults: an updated meta-analysis and best practice recommendations. N. S. W. $743 \quad$ Public Health Bull. 22, 78-83. doi:10.1071/NB10056

744 Shigematsu, R., 2014. Effects of exercise program requiring attention, memory and imitation on 745 cognitive function in elderly persons: a non-randomized pilot study. J. Gerontol. Geriatr. $746 \quad$ Res. 3, 1-6. doi:10.4172/2167-7182.1000147

747 Shigematsu, R., Okura, T., 2006. A novel exercise for improving lower-extremity functional 748 fitness in the elderly. Aging Clin. Exp. Res. 18, 242-248. doi:1464 [pii]

749 Shigematsu, R., Okura, T., Nakagaichi, M., Tanaka, K., Sakai, T., Kitazumi, S., Rantanen, T., 750 2008a. Square-Stepping Exercise and Fall Risk Factors in Older Adults: A Single-Blind, 751 Randomized Controlled Trial. Journals Gerontol. Ser. A Biol. Sci. Med. Sci. 63, 76-82. 752 doi:10.1093/gerona/63.1.76

753 Shigematsu, R., Okura, T., Sakai, T., Rantanen, T., 2008b. Square-stepping exercise versus 
strength and balance training for fall risk factors. Aging Clin. Exp. Res. 20, 19-24. doi:4378

755

756

757

758

759

760

761

762

763

764

765

766

767

768

769

770

771

772

773

774

775

776

[pii]

Smith, E., Cusack, T., Blake, C., 2016. The effect of a dual task on gait speed in community dwelling older adults: A systematic review and meta-analysis. Gait Posture 44, 250-258. doi:10.1016/j.gaitpost.2015.12.017

Snijders, A.H., van de Warrenburg, B.P., Giladi, N., Bloem, B.R., 2007. Neurological gait disorders in elderly people: clinical approach and classification. Lancet Neurol. 6, 63-74. doi:10.1016/S1474-4422(06)70678-0

Snowden, M., Steinman, L., Mochan, K., Grodstein, F., Prohaska, T.R., Thurman, D.J., Brown, D.R., Laditka, J.N., Soares, J., Zweiback, D.J., Little, D., Anderson, L.A., 2011. Effect of exercise on cognitive performance in community-dwelling older adults: Review of intervention trials and recommendations for public health practice and research. J. Am. Geriatr. Soc. 59, 704-716. doi:10.1111/j.1532-5415.2011.03323.x

Sperling, R.A., Aisen, P.S., Beckett, L.A., Bennett, D.A., Craft, S., Fagan, A.M., Iwatsubo, T., Jack, C.R., Kaye, J., Montine, T.J., Park, D.C., Reiman, E.M., Rowe, C.C., Siemers, E., Stern, Y., Yaffe, K., Carrillo, M.C., Thies, B., Morrison-Bogorad, M., Wagster, M. V, Phelps, C.H., 2011. Toward defining the preclinical stages of Alzheimer's disease: recommendations from the National Institute on Aging-Alzheimer's Association workgroups on diagnostic guidelines for Alzheimer's disease. Alzheimers. Dement. 7, 28092. doi:10.1016/j.jalz.2011.03.003

Springer, S., Giladi, N., Peretz, C., Yogev, G., Simon, E.S., Hausdorff, J.M., 2006. Dual-tasking effects on gait variability: The role of aging, falls, and executive function. Mov. Disord. 21, 950-957. doi:10.1002/mds.20848 
777 Stuckey, M.I., Knight, E., Petrella, R.J., 2012. The Step Test and Exercise Prescription Tool in

778 Primary Care : A Critical Review. Crit. Rev. Phys. Rehabil. Med. 24, 109-123.

779 Studenski, S., Perera, S., Patel, K., Rosano, C., Faulkner, K., Inzitari, M., Brach, J., Chandler, J., 780 Cawthon, P., Connor, E.B., Nevitt, M., Visser, M., Kritchevsky, S., Badinelli, S., Harris, T., 781 Newman, A.B., Cauley, J., Ferrucci, L., Guralnik, J., 2011. Gait speed and survival in older 782

783

784

785

786

787

788

789

790

791

792

793

794

795

796

797

798

799 adults. JAMA 305, 50-58. doi:10.1001/jama.2010.1923

Suzuki, T., Shimada, H., Makizako, H., Doi, T., Yoshida, D., Tsutsumimoto, K., Anan, Y., Uemura, K., Lee, S., Park, H., 2012. Effects of multicomponent exercise on cognitive function in older adults with amnestic mild cognitive impairment: a randomized controlled trial. BMC Neurol. 12, 128. doi:10.1186/1471-2377-12-128

Teixeira, C.V.L., Gobbi, S., Pereira, J.R., Vital, T.M., Hernandéz, S.S.S., Shigematsu, R., Gobbi, L.T.B., 2013. Effects of square-stepping exercise on cognitive functions of older people. Psychogeriatrics 13, 148-156. doi:10.1111/psyg.12017

Verghese, J., Annweiler, C., Ayers, E., Barzilai, N., Beauchet, O., Bennett, D.A., Bridenbaugh, S.A., Buchman, A.S., Callisaya, M.L., Camicioli, R., Capistrant, B., Chatterji, S., De Cock, A.M., Ferrucci, L., Giladi, N., Guralnik, J.M., Hausdorff, J.M., Holtzer, R., Kim, K.W., Kowal, P., Kressig, R.W., Lim, J.Y., Lord, S., Meguro, K., Montero-Odasso, M., MuirHunter, S.W., Noone, M.L., Rochester, L., Srikanth, V., Wang, C., 2014. Motoric cognitive risk syndrome Multicountry prevalence and dementia risk. Neurology 83, 718-726. doi:10.1212/WNL.0000000000000717

Woollacott, M., Shumway-Cook, A., 2002. Attention and the control of posture and gait: A review of an emerging area of research. Gait Posture 16, 1-14. doi:10.1016/S09666362(01)00156-4 
800 Yogev-Seligmann, G., Hausdorff, J.M., Giladi, N., 2008. The role of executive function and

801 attention in gait. Mov. Disord. 23, 329-342. doi:10.1002/mds.21720

802 You, J.H., Shetty, A., Jones, T., Shields, K., Belay, Y., Brown, D., 2009. Effects of dual-task

803 cognitive-gait intervention on memory and gait dynamics in older adults with a history of

804 falls: A preliminary investigation. NeuroRehabilitation 24, 193-198. doi:10.3233/NRE-

$805 \quad 2009-0468$

806 Young, J., Angevaren, M., Rusted, J., Tabet, N., 2015. Aerobic exercise to improve cognitive

807 function in older people without known cognitive impairment. Cochrane Libr. 4,

$808 \quad$ CD005381. doi:10.1002/14651858.CD005381.pub4

809 Zanotto, T., Bergamin, M., Roman, F., Sieverdes, J.C., Gobbo, S., Zaccaria, M., Ermolao, A.,

810 2014. Effect of exercise on dual-task and balance on elderly in multiple disease conditions.

811 Curr. Aging Sci. 7, 115-136. doi:10.2174/1874609807666140328095544

812 Zhuang, J., Huang, L., Wu, Y., Zhang, Y., 2014. The effectiveness of a combined exercise

813 intervention on physical fitness factors related to falls in community-dwelling older adults.

814 Clin. Interv. Aging 9, 131-40. doi:10.2147/CIA.S56682

815 